\title{
Supporting Lesbian, Gay, Bisexual, \& Transgender Inclusivity in Long-Term Care Homes: A Canadian Perspective
}

\author{
Tamara Sussman, ${ }^{1}$ Shari Brotman, ${ }^{1}$ Heather Maclntosh, ${ }^{1}$ Line Chamberland, ${ }^{2}$ Judith MacDonnell, ${ }^{3}$ \\ Andrea Daley, ${ }^{4}$ Jean Dumas, ${ }^{5}$ and Molly Churchill ${ }^{1}$
}

\begin{abstract}
RÉSUMÉ
Il est indispensable que les foyers de soins de longue durée (FSLD) soient sensibilisés aux besoins des aîné(e)s lesbiennes, gays, bisexuels et transgenres. Considérant que le degré d'intégration de stratégies recommandées en ce sens dans le secteur des FSLD est inconnu, cette étude qualitative canadienne vise à présenter les résultats de deux initiatives principales ciblant cette lacune : des entrevues semi-structurées téléphoniques ont ainsi été menées avec des administrateurs de FSLD au Canada concernant les stratégies adoptées pour appuyer l'inclusion des personnes LGBT $(n=32)$ et une rencontre de deux jours organisée sur la thématique de l'inclusivité des personnes LGBT dans les FSLD ( $n=25)$ a été organisée, le contenu des discussions de cette rencontre ayant été analysé dans la présente étude. Nos résultats révèlent que la formation concernant l'inclusivité LGBT était la stratégie la plus fréquemment adoptée dans les FSLD participant à l'étude. Ils montrent aussi que les pratiques plus visibles pour les résidents et les familles, telles que les programmations thématiques, l'utilisation d'un vocabulaire ou de symboles LGBT ou les initiatives conjointes avec les communautés LGBT étaient moins fréquentes, étant donné l'anticipation de réactions négatives de la part des résidents ou de leur famille. L'importance et les avantages de stratégies intégrées incluant le personnel, les résidents et les familles sont discutés.
\end{abstract}

\begin{abstract}
It is critical to ensure that long-term care (LTC) homes are sensitive to the needs of lesbian, gay, bisexual, and transgender (LGBT) older adults. However, the extent to which the LTC home sector has adopted recommended strategies is unknown. This qualitative study reports findings from two initiatives: Semi-structured telephone interviews with Canadian LTC home administrators on strategies adopted to support LGBT inclusivity $(n=32)$, and discussions with participants attending a 2-day meeting on supporting LGBT inclusivity in LTC $(n=25)$. We found that LGBT inclusivity training was the most commonly adopted strategy among the LTC homes surveyed. Study findings further suggested that practices more visible to residents and families, such as LGBT-themed programming, inclusive language and symbols, or joint initiatives with LGBT communities, were less commonly adopted because of anticipated negative resident/family reactions. The importance and benefits of comprehensive strategies that include staff, residents, and family are discussed.
\end{abstract}

1 School of Social Work, Faculty of Arts, McGill University

2 Department of Sexology, Faculty of Social Sciences, Université du Québec à Montréal

3 Faculty of Health, Nursing \& Environmental Studies, York University

4 School of Social Work, Faculty of Arts \& Professional Studies, York University

5 Faculty of Medicine and Health Sciences, University of Sherbrooke

Manuscript received: / manuscrit reçu : 17/12/16

Manuscript accepted: / manuscrit accepté : 22/08/17

Mots-clés : vieillissement, soins de longue durée, lesbienne, gay, bisexuel, transgenre, inclusivité, diversité, foyers de soins de longue durée

Keywords: aging, long-term care, lesbian, gay, bisexual, transgender

La correspondance et les demandes de tirés-à-part doivent être adressées à : / Correspondence and requests for offprints should be sent to:

Tamara Sussman, Ph.D.

McGill University

School of Social Work

3506 University Street, Room 305

Montreal, QB H3A 2A7

$<$ tamara.sussman@mcgill.ca>

Canadian Journal on Aging / La Revue canadienne du vieillissement 37 (2) : 121-132 (2018)

(c) Canadian Association on Gerontology 2018. This is an Open Access article, distributed under the terms of the Creative

Commons Attribution licence (https://creativecommons.org/licenses/by/4.0/), which permits unrestricted re-use,

distribution, and reproduction in any medium, provided the original work is properly cited.

doi: $10.1017 /$ S0714980818000077 


\section{Background and Literature Review}

Between 18 per cent and 33 per cent of older adults over age 85 in Canada and the United States reside in congregate living facilities such as retirement residences, assisted living facilities, and nursing homes (herein referred to as long-term care [LTC] homes) (Summerfield \& Babb, 2004; National Institute on Aging, 2006; Banerjee, 2009). Although the percentage of lesbian, gay, bisexual, and transgender (LGBT) older adults in LTC homes is unknown, LGBT older adults who are cognitively or physically disabled are at heightened risk of relocation to LTC facilities. This is because many LGBT adults in advanced age (over 80) live alone (Adelman, Gurevitch, de Vries, \& Blando, 2006; Cahill, South, \& Spade, 2000; Fredriksen-Goldsen, Kim, Barkan, Muraco, \& Hoy-Ellis, 2013; Services and Advocacy for GLBT Elders (SAGE), 2014; Wallace, Cochran, Durazo, \& Ford, 2011), may not have adult children, partners, or other family/friends who can support community care (de Vries, 2009; Muraco \& Fredriksen-Goldsen, 2011), and have limited financial resources from which to purchase care (Brennan-Ing, Seidel, Larson, \& Karpiak, 2014; Grant, 2010; Grant et al., 2011; James et al., 2016).

Research on LGBT older adults' experiences with LTC homes suggests that there are critical improvements required to ensure that these environments are sensitive and inclusive to the needs, care preferences, and experiences of LGBT older adults (Brotman, Ferrer, Sussman, Ryan, \& Richard, 2015; Johnson, Jackson, Arnette, \& Koffman, 2005; Jones, 2011; MetLife Mature Market Institute \& The Lesbian and Gay Aging Issues Network of the American Society on Aging, 2010). Recommendations from leading activists and researchers include the development of LGBT community-LTC sector alliances, outreach to LGBT communities, inclusive employment practices, and staff training (Brotman, Watkins, \& Ryan, 2010; Moore, 2009; Toronto Long-Term Care Homes and Services, 2008). However, the extent to which these recommendations have been adopted into practice in Canada and elsewhere is unknown.

In this article we report findings from a research project on the current state of LGBT inclusivity in LTC homes. The project featured interviews with Canadian LTC home administrators and deliberations in a twoday meeting with Canadian LGBT advocates, LTC home service providers, researchers, and LGBT older adults wherein participants (a) described initiatives taken within the Canadian LTC home sector to address LGBT issues, and (b) identified gaps, challenges, and solutions regarding implementation of inclusive strategies. LGBT-inclusive strategies were defined as actions taken to acknowledge or address the experiences or needs of LGBT older adults in LTC, with the aim of moving from an environment of indifference or tolerance to one of solidarity (Brotman \& Ryan, 2001).

An emerging literature is documenting the needs, experiences, and perceptions of LGBT older adults living in LTC homes. Findings suggest that communityresiding LGBT older adults believe that discrimination is prevalent in LTC homes and that these congregate living environments have taken only limited, if any, steps towards guarding against discriminatory practices (Brotman, Ryan, \& Cormier, 2003; Brotman et al., 2015; Furlotte, Gladstone, Cosby, \& Fitzgerald, 2016; Jackson, Johnson, \& Roberts, 2008; Johnson, Jackson, Arnette, \& Koffman, 2005; Jones, 2011; MetLife Mature Market Institute \& The Lesbian and Gay Aging Issues Network of the American Society on Aging, 2010; Smith, McCaslin, Chang, Martinez, \& McGrew, 2010). A report authored by the National Senior Citizens Law Center (NSCLC) (2011) emphasized the depth and breadth of these fears, revealing that only 22 per cent of community-residing LGBT older adults in the United States (60/278 respondents) believed that residents of LTC homes can be open with staff about their sexual orientation or gender identity (NSCLC, 2011). The voices of $\mathrm{LGB}^{1}$ adults residing in LTC homes appear to affirm these fears, with most reporting that they feel the need to hide their sexual orientation to prevent rejection, ostracization, and neglect from both staff and residents (Stein, Beckerman, \& Sherman, 2010).

This feeling of needing to hide their sexual orientation is concerning, since non-disclosure of sexual orientation has been negatively associated with the quality of health care provided (Stein \& Bonuck, 2001; Donaldson, Asta, \& Vacha-Haase, 2014). Non-disclosure also appears to result in LGB residents feeling isolated, lonely, and anxious (Gardner, de Vries, B., \& Mockus, 2014; Stein et al., 2010). Some literature has emphasized that the self-protective strategy of non-disclosure may be an impossible strategy for transgender older adults when receiving care in a residential setting, due to the inevitable outing that occurs during physical care when anatomical sex and identified gender do not align (Brotman et al., 2015). This places transgender older adults at heightened risk of alienation and discrimination in LTC homes from residents and staff who are or may be transphobic.

Research conducted in both Canada and the United States has also revealed a lack of awareness and training among service providers and administrators employed in LTC homes. Of particular concern is an overwhelming presumption that current approaches to "diversity" are sufficient to meet the needs of the LGBT population (Bell, Bern-Klug, Kramer, \& Saunders, 2010; New York Department of Health and Mental 
Hygiene, 2007; Brotman et al., 2015; Chamberland, 2003; McFarland \& Sanders, 2003), and the presence of organizational policies and practices that presume heterosexuality and cisnormativity ${ }^{2}$ (Hébert, Chamberland, \& Enriquez, 2013). These policies and practices include administrative forms that ask about husbands/wives rather than partners/spouses, binary categorization of gender as male or female, failure to name sexual orientation or gender identity in anti-discrimination policies, and images within the facilities that depict only heterosexual couples and/or cissexual individuals.

On a more promising note, staff attitudes within broader gerontological services appear to be shifting, with many staff in the continuum of aging services expressing openness to LGBT-specific initiatives (Daley \& MacDonnell, 2011; Daley, MacDonnell, \& St. Pierre, 2016; Hughes, Harold, \& Boyer, 2011). Some partnerships between LGBT advocates, scholars, and LTC home service providers have emerged, resulting in the development of practice guidelines to support LGBT inclusivity within the LTC environment. For example, in Canada, a conglomerate of municipally run and regulated LTC homes partnered with LGBT advocates, with a specialization in aging, and scholars to develop a toolkit, which outlines six areas requiring action to address the pressing need to become LGBT inclusive. These include (1) delivering programs and services that are sensitive to the history of oppression of LGBT people, (2) creating governance structures (policies, procedures, committees) that promote LGBT inclusivity, (3) generating hiring policies that welcome and promote people from LGBT communities, (4) creating an LGBT-welcoming physical and relational environment, (5) consulting with LGBT people about their concerns and ensuring a transparent process of complaints, and (6) engaging in partnerships and outreach with LGBT people and organizations (Toronto Long-Term Care Homes and Services, 2008).

Similar frameworks have been proposed to guide LGBT inclusivity in publicly funded home care programs (Daley et al., 2016) and community-based gerontological services (Fredriksen-Goldsen, Hoy-Ellis, Goldsen, Emlet, \& Hooyman, 2014). However, the extent to which these recommendations have been adopted into practice in the Canadian LTC home sector has yet to be examined. Further, with most research conducted in the United States, a limited body of knowledge evaluates specifically how the Canadian LTC home sector has (or has not) been implementing practices to address or identify the needs of LGBT older adults.

This article reports findings from two main initiatives. The first initiative was a telephone-based interview with administrators from Canadian LTC homes selfidentified or recognized by LGBT advocacy groups as taking steps towards LGBT inclusivity. These interviews served to identify the strategies being considered and implemented in that subset of LTC environments that are attempting to respond to this issue. The second initiative was a two-day meeting with LGBT advocates, LTC home service providers, researchers, and LGBT older adults which took place following the telephone-based interviews. This meeting provided participants with the opportunity to discuss the LGBTinclusive practices that have been implemented within the Canadian LTC sector, and to consider an overall strategy for identifying and implementing a broader based approach to LGBT inclusivity within LTC homes.

The two initiatives we describe here were conducted in accordance with the standards of the Tri-Council Policy Statement for Ethical Conduct for Research Involving Humans (Canadian Institutes of Health Research, Natural Sciences and Engineering Research Council of Canada, and Social Sciences and Humanities Research Council of Canada, 2010). Procedures related to informed consent, data management, and dissemination were approved by the Office of Research Ethics Board at McGill University.

\section{Methods}

We elected to focus our data collection in six urban cities located in three Canadian provinces (British Columbia, Ontario, and Quebec). Toronto, Vancouver, and Montreal were first selected for recruitment because they represent large urban centres with high populations of LGBT older adults (Canada Census, 2006) and a wide variety of services and supports for LGBT older adults. We added the capital cities from each of these provinces (Ottawa, Victoria, and Quebec City) to ensure broader representation of facilities from each province. It was felt that these six cities would provide a reasonably complete provincial representation of initiatives undertaken in urban Canada. We excluded rural areas because we felt we would find the most progressive initiatives in urban centres, where there are more LGBT services and initiatives (Lee \& Quam, 2013).

For the purposes of this study, LTC homes included (a) publicly regulated nursing homes which typically cater to older adults with high care needs, are accessed through a single entry point in a health network, and have set fees and clear rules about service provision through provincial legislation; and (b) retirement residences which are more loosely regulated, cater to semiautonomous older adults, do not have capped user fees, and are usually accessed directly (i.e., any older 
adult or family can apply for admission directly through the home's administration). Purposive sampling was used to recruit representatives from LTC homes whose online promotional material suggested inclusivity of LGBT older adults (i.e., they placed a rainbow symbol on their website, they included a bill of rights on their website that referred to rights related to sexual orientation or gender identity). Additionally, facilities were included that were identified through snowball sampling (through respondents) as having undertaken some initiatives related to LGBT older adults. We focused on facilities identified as taking steps towards LGBT inclusivity because we wanted to move the knowledge base forward beyond documenting gaps to highlighting how, to what extent, and under what circumstances initiatives have been adopted within the Canadian LTC home sector. Ultimately, we hope that this work will inform a series of strategies that can be employed by LTC homes to improve access and equity for the growing number of LGBT older adults anticipated to relocate to LTC in the coming years.

Using the strategy identified above, an initial online search yielded $11^{3}$ facilities that self-identified as taking steps towards LGBT inclusivity via online material. A further 23 facilities were identified through snowball sampling. More specifically, administrators from the 11 identified homes or members from LGBT organizations in the six cities wherein the interviews were conducted identified these facilities as having done work in this area. Two of the 23 facilities identified through snowball sampling were excluded upon initial screening as no steps towards LGBT inclusivity had been taken. Although these two organizations were named by others as potentially inclusive, they had not made any efforts to raise awareness or address the needs of LGBT older adults. Administrators in the remaining 32 facilities were contacted via email or telephone and invited to participate in a telephone interview describing their home's policies, programs, and initiatives related to LGBT inclusivity. All 32 facilities agreed to participate. Importantly, we found no organizations whose promotional materials suggested inclusivity (e.g., a rainbow sign) that had not also undertaken concrete steps towards some level of inclusion.

\section{Telephone-Based Interviews: Data Collection and Analysis}

We used a semi-structured interview guide to inform the telephone interviews. The guide prompted participants to (1) broadly describe LGBT initiatives being undertaken in their facility; (2) identify challenges and solutions regarding implementation of initiatives;
(3) comment on the perceived impact of initiatives undertaken; and (4) identify plans to promote LGBT inclusivity.

Responses to all telephone interviews were recorded in the form of field notes by one research assistant, who conducted all the interviews. The notes from each interview were analysed in three stages. In the first stage, we undertook a conventional content analysis to categorize the described practices (Hsieh \& Shannon, 2005). This process yielded eight distinct categories that represented different practices LTC homes reported as having adopted to address LGBT inclusivity (e.g., staff training, LGBT-themed programming). In the second stage, one additional category, comprehensive strategy, was created based on further analysis of the interviews and trends described in the literature. This category was used to represent facilities that adopted multifaceted practices at multiple levels, including services and programs, governance, community relations, and the physical environment. This type of multilevel approach has been recommended by experts (Daley \& MacDonnell, 2011; Fredriksen-Goldsen et al., 2014; Toronto Long-e). In the third and final stage, the frequency with which all nine categories were mentioned by each interviewee was recorded to provide a portrait of the most and least commonly endorsed initiatives. In this stage, we analysed general comments providing insights into why practices may or may not have been adopted. This analysis helped to identify perceived barriers, solutions, and gaps.

\section{Meeting Deliberations: Data Collection and Analysis}

A purposeful snowballing process was what we used to invite participants from the three Canadian provinces (Ontario, Quebec, and British Columbia) represented in the telephone interviews to a two-day meeting held in Montreal. Although the goal of this meeting was to reflect on research and practice priorities to increase LGBT inclusivity in the Canadian LTC sector, the deliberations reported and analysed in this article were those focused on practice-related discussions.

Initially, we solicited potential participants by phone who were known to be doing work on LGBT older adults' access and equity issues and asked them to identify others they felt had relevant interest and/or expertise. Second, we invited organizations and facilities identified in the telephone interviews as showing leadership in the area to participate and/or to identify other participants. A total of 31 potential participants were invited to participate in this meeting; 25 of these individuals attended and participated. Conference participants included LTC home administrators and service providers (4); community advocates (9); researchers (9); and students (3), collectively representing 
the salient demographics of older adults, partners of individuals currently receiving care, and members of LGBT communities. Participants from Ottawa, Victoria, Vancouver, Montreal, and Toronto attended, representing five of the six cities included in the first analysis.

The first day of this planned meeting included three plenary panels that provided an overview of LGBT LTC initiatives in Ontario, British Columbia, and Quebec. Presentations added further depth to some of the initiatives identified in our telephone interviews. On the second day, three small-group deliberations were conducted using an adapted nominal group technique (Moore, 1987) to further discuss the current state of knowledge and practice regarding LGBT inclusivity and LTC and to identify barriers, solutions, and gaps related to moving research and practice forward in this sector. We focus here on exchanges that highlighted practice gaps, barriers, and solutions.

All meeting deliberations were tape-recorded and transcribed verbatim by the student participants. Notes were also taken by student representatives throughout the two-day planned meeting. We used a two-step thematic analysis to analyse the transcripts and notes emanating from group discussions and exchanges (Braun \& Clarke, 2006). In step one, a graduate-level research assistant compiled all text segments and notes that focused on practice issues and initiatives within LTC. In step two, the first author (TS) reviewed text excerpts alongside the issues and initiatives described in the telephone interviews. More specifically, these texts were examined to further identify challenges, solutions, and gaps related to LGBT inclusivity expressed by participants.

\section{Findings}

The type and location of facilities included in the telephone interviews and the frequency with which all practices were mentioned by LTC home administrators are outlined in Table 1.

Most facilities identified as inclusive were in Ontario $(24 / 32 ; 75 \%)$, and just over half of the facilities identified as inclusive were nursing homes (18/32; 56\%). Only $3 / 32(9 \%)$ of the facilities identified as inclusive were privately developed to service the LGBT community specifically. These facilities were all retirement homes located in Quebec intended to service LGBT older adults with limited care needs and financial capacity to pay market rent.

\section{Telephone Survey Results}

Staff training was the initiative most frequently adopted by all facilities with $22 / 32(69 \%)$ adopting this strategy. Forty-five per cent $(10 / 22)$ of the facilities that offered staff training provided it to all staff. The remainder provided training to management $(9 / 22 ; 41 \%)$ or professional staff only (e.g., social workers, occupational therapists, nurses) $(3 / 22 ; 14 \%)$.

Offering LGBT-themed programming was the next most frequent initiative undertaken by 14/32 (44\%) representing the participating LTC homes. Themed programming was typically offered at least once a year and was either educationally focused (i.e., screening films with LGBT issues and hosting roundtables on LGBT issues) or recreationally focused (i.e., LGBTthemed movies and barbeques honouring Pride Week).

Table 1: LGBT inclusivity initiatives in long-term care homes in three Canadian provinces

\begin{tabular}{|c|c|c|c|c|}
\hline LTC Home Types \& Practices ${ }^{a}$ & $\begin{array}{c}\text { Ontario } \\
n\end{array}$ & $\begin{array}{c}\text { Quebec } \\
n\end{array}$ & $\begin{array}{c}\text { British Columbia } \\
n\end{array}$ & $\begin{array}{c}\text { Total } \\
n\end{array}$ \\
\hline \multicolumn{5}{|l|}{ Type of Facility } \\
\hline Retirement Home & 9 & 5 & 0 & 14 \\
\hline Nursing Home & 15 & 1 & 2 & 18 \\
\hline Private; LGBT-specific & 0 & 3 & 0 & 3 \\
\hline Public; general population & 24 & 3 & 2 & 29 \\
\hline \multicolumn{5}{|l|}{ Practices Adopted } \\
\hline Staff training & 20 & 0 & 2 & 22 \\
\hline LGBT-themed programming & 7 & 6 & 1 & 14 \\
\hline LGBT advisory or steering committee & 10 & 0 & 1 & 11 \\
\hline Participation in LGBT events/networks & 7 & 3 & 1 & 11 \\
\hline LGBT symbols in home environment & 2 & 5 & 1 & 8 \\
\hline Attention to language & 2 & 5 & 1 & 8 \\
\hline Outreach/recruitment to LGBT community & 4 & 3 & 1 & 8 \\
\hline Official partnership with LGBT organization & 2 & 3 & 0 & 5 \\
\hline Comprehensive approach & 2 & 3 & 1 & 6 \\
\hline
\end{tabular}

a Nursing homes represent facilities that cater to residents with heavy care needs and are referred to provincially as LTC homes (Ontario), residential care facilities (British Columbia) or centres d'hébergement \& de soins de longue durée (CHSLDs) (Quebec). Retirement homes represent facilities that cater to residents with lighter care needs and are referred to provincially as retirement homes (Ontario), assisted living facilities (British Columbia) or intermediate resources (Quebec). 
According to respondents who had offered this type of programming, benefits included supporting a culture of acceptance and raising awareness among residents. In one case, an administrator recounted that residents who had participated in educationally focused programming started to request changes to other programming in the home, which was identified as being heteronormative. ${ }^{4}$ In this instance, educational programming generated the formation of alliances between gay and straight residents. Those who had not engaged in LGBT-themed programming (18/32; 56\%) expressed fears and concerns regarding residents' reactions to these types of programs.

A third of the LTC homes (11/32; 34\%) had developed an LGBT advisory structure either internally (e.g., organizing a group of service providers and users within the home to oversee LGBT initiatives) or externally (e.g., sending an LTC representative from their home to participate in a pre-existing LGBT network). Those who had adopted an advisory structure within their LTC homes reported that this internal structure supported further changes within the home.

One quarter $(8 / 32 ; 25 \%)$ of the LTC homes had either (a) adopted permanent measures to communicate inclusivity to residents and families (e.g., hanging symbols in the home such as rainbow flags, developing charters of rights which specifically named LGBT inclusivity, adapting language used on forms and renaming programs), or (b) undertaken active outreach to the LGBT community (e.g., inviting seniors from an LGBT organization to come to the facility for a social event with residents, asking LGBT organizations to advertise their facility to its older members, and recruiting volunteers from LGBT organizations to interact with residents and become familiar with the facility).

One fifth $(6 / 32 ; 19 \%)$ of the LTC homes had adopted a comprehensive strategy. Three of the facilities that adopted a comprehensive strategy were publicly funded and regulated nursing homes. The other facilities that adopted a comprehensive strategy were the three private retirement homes built specifically to cater to the LGBT community. Administrators from two of the three publicly funded nursing homes that adopted this comprehensive approach recalled LGBT residents who had disclosed their sexual orientation or gender identity within their facilities because of the supportive atmosphere they had created.

In sum, our telephone interviews revealed that most LGBT-inclusive strategies within LTC included some form of staff training. Those that extended initiatives beyond staff - by either offering LGBT-themed programming to residents or adopting other strategies more visible to residents (inclusive language, outreach to LGBT community) - recounted examples of raised resident awareness and comfort with selfdisclosure among LGBT older adults residing in their homes. Changing practices and physical symbols within the home and outreach to the LGBT community were initiatives that were less frequently adopted. According to respondents, these initiatives were often preceded by the establishment of an infrastructure (e.g., formalized advisory board, LTC home-LGBT organization alliance) that helped to identify initiatives that could be undertaken and oversee their adoption into practice).

\section{Conference Deliberations}

Three primary themes emerged in the analysis of the results of the meeting deliberations, which added further depth to some of the themes noted in the telephone surveys. These included the importance of LGBT inclusivity in nursing homes, multi-level staff training as a critical step, and the pressing need for resident engagement in LGBT strategies.

\section{Importance of LGBT Inclusivity at the Nursing Home Level}

Conference participants supported the importance of promoting LGBT inclusivity in all congregate living environments. However, most conference participants spoke of the pressing need to integrate LGBT inclusivity within the public nursing home sector because relocations to this level of care are typically sudden, unanticipated, and based on bed availability rather than choice. As one conference participant said,

And you know if you're an emergency you just go to the next available bed. So, for example, if something were to happen to my partner or to me and she had to go into care, forget about anything close to being gay friendly ... it's the next bed.

Another conference participant, reiterating the pressure to accept any facility with an opening, stated that, "if you are on a five-year waiting list you're just so happy to get a spot anywhere". These conference participants highlighted that many LGBT older adults with deteriorating health would not have the luxury of selecting a facility known to them to be LGBT inclusive. They therefore emphasized the importance of adopting strategies for inclusivity which target the public nursing home system.

One conference participant who had relocated from one nursing home environment with no LGBT initiatives to another that had adopted a comprehensive strategy described the difference it made for her as follows: "I went from feeling like a body to feeling like a whole person". The thought that older LGBT adults could end up in nursing homes which made them feel like person-less bodies affirmed the pressing need for 
the broad-based implementation of core initiatives in nursing homes across the country.

It is noteworthy that prioritizing a nursing level of care was not emphasized in our telephone surveys. This difference may be a result of the different mix of participants in the two initiatives. Our conference deliberations included a small group of LTC home service providers, alongside a group of LGBT advocates (who are highly aware of the limited resources LGBT community organizations have for supporting LTC inclusion), and LGBT older adults (who have faced or witnessed relocation to LTC). Our telephone surveys, by contrast, included LTC home administrators only, all of whom benefited from the support of LGBT organizations that helped them to implement LGBT-inclusive strategies in their respective facilities. Hence, these administrators may have been less implicated in the personal realities of facing relocation, or in meeting the demands of supporting inclusive strategies across the health and social service sector with limited resources.

\section{Multi-Level Staff Training as a First Step}

Most conference participants suggested that raising awareness through staff training was an important first step in helping administrators and practitioners realize the importance of creating an LGBT-inclusive environment in LTC. To be most effective, training needed to be offered to all staff, including upper-level administrators, middle managers, and front-line staff. This multi-level approach was perceived to be the only way to develop awareness, inclusivity, and openness in workers at all levels to champion the implementation of other strategies. Ongoing training that was part of a regular orientation program for staff was considered more desirable than one-off training due to the high staff turnover in the nursing home sector.

Participants noted that there was still a prevalence of LTC home administrators that declined the offer for training. For example, advocates described encountering service providers and administrators who said things such as "we don't have any LGBT clients here" or "we treat everyone the same [and do not require special training]". These statements suggest a lack of awareness that LGBT residents or family members may reside within or interact with their facilities, and that LGBT residents may have needs that are unique to them. Proactive outreach to promote the need for training was identified as an important potential solution to combat this barrier. However, LGBT organizations had limited capacity for this form of outreach due to tight budgets and limited staff resources. According to conference participants, those facilities that were already somewhat receptive to LGBT issues were those that most typically sought and/or accepted training.

\section{Resident Engagement in LGBT Strategies}

Engaging other residents (and their families) in LGBTinclusive strategies was emphasized as an important step towards supporting LGBT older adults' comfort within LTC homes. According to conference participants, without such engagement LGBT residents remain vulnerable to the homophobic and transphobic beliefs held by some of those with whom they co-reside. This could render them vulnerable to direct attacks by residents, or to isolating themselves from their LGBT community in an effort to hide their LGBT identity. One transgender participant who recalled visiting a friend in LTC stated,

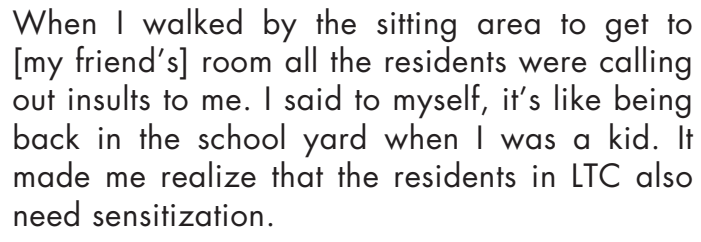
[my friend's] room all the residents were calling out insults to me. I said to myself, it's like being back in the school yard when I was a kid. It made me realize that the residents in LTC also need sensitization.

Other participants recounted stories whereby LGBT residents had cut themselves off from the LGBT community upon entry into LTC. They did this fearing visits from their community would "out" them to other residents.

Different strategies for resident engagement were discussed, including offering education and training to residents (and their families), and initiating resident consultations when a step is taken to implement a new LGBT-inclusive policy or practice. One LTC home service provider in attendance explained that when his LTC home decided to update their charter of resident rights to include sexual orientation and gender identity, they engaged in a series of consultations with other residents explaining this decision. He considered this engagement to be an important part of the implementation process.

\section{Study Limitations}

The findings from this study should be interpreted in light of four important limitations. First, the provincial portrait of LTC home initiatives provided through our survey results was based on data from two cities per province. Although we purposely selected the cities to provide a reasonably complete provincial representation of initiatives undertaken in Canada, it is possible that including more cities within the selected provinces would have yielded a different picture of provincial initiatives undertaken. Future research would benefit from comparing the results emanating from this study with other localities both within the selected provinces and 
more broadly across Canada. Comparisons between urban and rural areas would also be important. Second, to identify initiatives undertaken we relied on the combination of our own search and snowball sampling. Hence, the initiatives we identified may not represent all those undertaken in the localities we studied.

Third, the LTC homes included in our study serviced the general population of older adults. Potentially focusing on homes servicing particular cultural, ethnic, religious, and linguistic communities may have yielded different barriers and solutions not captured in our data (MacDonnell \& Daley, 2015). Finally, our study aimed to describe LGBT initiatives undertaken in the LTC home sector and to highlight barriers and solutions that hinder or support the implementation of inclusive strategies. Although this work yielded some data related to the perceived impact of inclusive strategies, future research would benefit from examining the effects of such initiatives using measurable outcomes for LGBT older adults residing in LTC, other residents, families, and staff.

\section{Discussion}

Our combined telephone surveys and conference deliberations uncovered some important trends in the adoption of LGBT-inclusive strategies within the Canadian LTC home sector and offer priorities and strategies that may support broader based implementation.

Our survey results revealed that the LGBT-inclusive initiatives undertaken in Canada were relatively equally balanced between retirement homes and nursing homes. Although the literature suggests that some LGBT older adults have a preference for relocating to retirement facilities, especially those geared towards LGBT older adults (Brennan-Ing et al., 2014; Ross, Scott, \& Wexler, 2003; Stein et al., 2010), our conference deliberations emphasized that the sickest and most economically vulnerable LGBT older adults will not be in a position to exercise these choices in relocation (Fraher \& Coffey, 2011; Sussman \& Dupuis, 2014). It is therefore imperative that Canadian nursing homes be provided with resources and incentives to support broader-based implementation of LGBT strategies across the country.

Our survey results suggested that Ontario appears to be leading the way in terms of implementation of LGBT-inclusive strategies in nursing homes, even after accounting for the larger proportion of nursing homes located in Ontario when compared to British Columbia and Quebec (Statistics Canada, 2012). Although 83 per cent $(15 / 18)$ of the nursing homes in our survey were located in Ontario, the actual proportion of Ontariobased nursing homes relative to British Columbia and Quebec is lower, at 60 per cent $(738 / 1,227)$ (Banerjee, 2007; Canadian Institute for Health Information, 2013).
The larger proportion of LGBT-inclusive nursing homes in Ontario may be a result of limitations in our sampling strategy, which adopted a purposeful and snowball sampling methodology to identify LGBT-inclusive LTC homes in participating localities. This higher proportion may also be in part a result of the leadership shown by a conglomerate of municipally run nursing homes in Toronto that participated in the collaborative development and subsequent implementation of a comprehensive strategy to support LGBT inclusivity. Importantly, 72 per cent of all Canadian nursing homes are chain owned and operated by private corporations (53\%), or municipal/provincial/territorial agencies (19\%) (Statistics Canada, 2012). Engaging senior board members and managers who are in a position to develop policy for a conglomerate of nursing homes may be one way of supporting broad-based implementation of LGBT-inclusive initiatives across the country. This engagement may require government support as some LGBT organizations have noted particular resistance among the private sector in terms of openness to LGBT training for staff (Chamberland, Beauchamp, Dumas, \& Kamgain, 2016).

LGBT inclusivity training was the most commonly adopted strategy of all LTC homes in our survey. This is reflective of findings from other Canadian researchers who have studied adoption of LGBT inclusivity strategies in home care (Daley et al., 2016). Our telephone interviews did not identify if staff training was a necessary component of developing an LGBTinclusive environment. However, studies on educational initiatives conducted with staff in gerontological settings have found training to significantly change staff knowledge and attitudes about the importance of adapting practices to support inclusion when that training (1) addresses the myths and realities of LGBT aging, (2) describes public policies of importance to LGBT older adults, and (3) identifies barriers and solutions to improving access for LGBT adults (Porter \& Krinsky, 2014). Further, conference deliberations suggested that ongoing training at all levels of the LTC home could be an important step to lead or sustain further change within organizations. Ongoing multi-level training was considered more desirable than one-off training due to the high staff turnover in the nursing home sector, which can range from 48-89 per cent in any given year (Castle, 2005). Others have similarly noted that ongoing training can make LGBT inclusivity a part of the fabric of an organization, thereby supporting a positive space for LGBT older adults (MacDonnell \& Daley, 2015). Such training could then be followed by the establishment of an infrastructure to support further initiatives. Unfortunately, LGBT- focused training for any level of staff is still rare within the LTC home sector (Almack, Ryder, \& Simpson, 2014; Bell et al., 2010). 
Our conference participants identified two barriers around the delivery of training for LTC home staff. First, not all LTC homes approached were interested in receiving such training, suggesting that those already open to the idea of LGBT inclusivity are the most likely to accept the invitation of training. Second, although LGBT organizations that typically provide this type of training recognize the need for outreach to promote its importance, most are not positioned to dedicate staff time for this purpose due to limited resources. A potential solution to these barriers would be to provincially mandate LTC homes to improve levels of expertise in LGBT issues within LTC and propose strategies for remediation. This strategy has been employed by provinces for many other areas of practice (see, for example, the Ontario Long-Term Care Homes Act, 2007, which includes regulations for training around behavioural issues and palliative care). To date, no Canadian province or territory has made it mandatory for LTC homes to engage in LGBT inclusivity training.

It is noteworthy that in the province of Quebec, the Ministry of Justice enacted a government plan to counteract homophobia (Justice Quebec, 2011) and a similar plan to counteract homophobia and transphobia, (Justice Quebec, 2017), which resulted in the Quebec Ministry of Health and Social Services providing some funding for LGBT sensitivity training to health and social service agencies that requested it. Although the province is commended for making legislative progress in this area, our findings suggest that the action plan and funding commitment has not gone far enough to ensure uptake. First, by only funding direct requests, no financial support is provided to dedicate staff time to outreach. Second, the funding thus far has not been adequate enough to fund training for all organizations in the sector that were interested. Third, as in other provinces these initiatives are, to date, voluntary for LTC homes.

Finally, and perhaps most importantly, our study findings revealed that multi-level strategies, including the development of an infrastructure to guide practices and offer educationally oriented LGBT programming to residents, could result in the development of safer and more inclusive environments for LGBT older adults. Those homes that had engaged in comprehensive strategies described generally positive reactions, including the development of alliances between gay and straight residents that began to promote other changes within the home.

Such steps could also serve as a protection against overt intolerance described in the broader literature and experienced by some participants in our study, as it would generate a community of allies among residents who could collectively speak out against homophobic and transphobic resident reactions (Donaldson et al., 2014).
At this point, it seems that the alliances described by our study participants evidenced resident awareness of and sensitivity to LGB issues, suggesting that concerted efforts may be needed to encourage similar alliances to support transgender older adults. Such resident alliances may be particularly meaningful for transgender older adults whose negative experiences with health professionals have reinforced the belief that acceptance of their transgender identity is unlikely, if not impossible (Hébert, Chamberland, \& Enriquez, 2015).

One of the largest barriers that staff of LTC homes identified concerning broader resident engagement was the fear of negative resident reactions towards such initiatives. It is possible that ageist attitudes of staff (i.e., regarding older adults as more rigid and less tolerant than other cohorts) contributed to this barrier (Dobbs et al., 2008; Kane \& Kane, 2005). Providing and sharing examples of positive resident engagement, such as the ones described by the participants in our study, could serve to overcome this barrier and facilitate broader based inclusion of residents in LGBT strategies.

\section{Conclusion}

LGBT inclusivity strategies are beginning to emerge in the Canadian LTC home sector. Most commonly, these strategies focus on raised awareness for staff through the provision of one-time or ongoing training. Ongoing training at all levels may be an important step in awakening staff regarding LGBT residents' fears of disclosure or discomfort in an environment that presumes heterosexuality or cisnormativity. However, comprehensive initiatives that create infrastructures to engage residents and families appear to support the movement from an environment of tolerance to one of solidarity and inclusion. Future research would benefit from examining the effects of such comprehensive initiatives on LGBT older adults, other residents, families, and staff.

\section{End Notes}

1 We purposefully use $L G B T, L G$, or $L G B$ in this article to indicate which communities are represented in a referenced study or report.

2 The term cis is a label (as in cissexual/cisgender) which refers to those "who have only ever experienced their subconscious and physical sexes as being aligned" (Bauer et al., 2009 , p. 349). Cisnormativity refers to the ways in which institutional norms and social practices reproduce assumptions of a societal gender binary, in which biological sex aligns with gender identity and expression.

3 Since the time of writing, one additional nursing home has added content to their online material supporting LGBT inclusivity. This home had already been included in the study sample through snowballing. 
4 Heteronormative refers to the ways in which institutional norms and social practices reproduce assumptions that everyone is heterosexual and that heterosexuality is superior to all other sexualities (Fenway Institute, 2017).

\section{References}

Adelman, M., Gurevitch, J., de Vries, B., \& Blando, J. (2006). Open house: Community building and research in the LGBT aging population. In D. Kimmel, T. Rose, \& S. David (Eds.), Lesbian, gay, bisexual, and transgender aging: Research and clinical perspectives, (pp. 247-264). New York, NY: Columbia University Press.

Almack, K., Ryder, S., \& Simpson, P. (2014). Care home survey: Knowledge, attitude and practices concerning LGBT residents (Unpublished report). Nottingham, ENG: University of Nottingham.

Banerjee, A. (2007). An overview of long-term care in Canada and selected provinces and territories. Toronto, $\mathrm{ON}$ : Women and Health Care Reform Group, York University.

Banerjee, A. (2009). Long-term care in Canada. An overview. In P. Armstrong, M. Boscoe, B. Clow, K. Grant, M. Haworth-Brockman, B. Jackson, A. Pederson, ... \& J. Springer (Eds.), A place to call home. Long-term care in Canada (pp. 29-57). Halifax, NS: Fernwood.

Bauer, G. R., Hammond, R., Travers, R., Kaay, M., Hohenadel, K. M., \& Boyce, M. (2009). "I don't think this is theoretical. This is our lives": How erasure impacts healthcare for transgender people. Journal of the Association of Nurses in AIDS Care, 20(5), 348-361.

Bell, S. A., Bern-Klug, M., Kramer, K. W. O., \& Saunders, J. B. (2010) Most nursing home social service directors lack training in working with lesbian, gay, and bisexual residents, Social Work in Health Care, 49(9), 814-831.

Braun, V., \& Clarke, V. (2006). Using thematic analysis in psychology. Qualitative Research in Psychology, 3(2), 77-101.

Brennan-Ing, M., Seidel, L., Larson, B., \& Karpiak, S. (2014). Social care networks and older LGBT adults. Challengers for the future. Journal of Homosexuality, 61(1), 21-52.

Brotman, S., Ferrer, I., Sussman, T., Ryan, B., \& Richard, B. (2015). Access and equity in the design and delivery of health and social care to LGBTQ seniors: A Canadian perspective. In N. Orel \& C. Fruhauf (Eds.), Lesbian, gay, bisexual and transgender older adults and their families: Current research and clinical applications (pp. 111-140). Washington, DC: American Psychological Association.

Brotman, S., \& Ryan, B. (2001). Critical issues in practice with gay, lesbian, bisexual and two spirit people ad communities. Montreal, QC: McGill School of Social Work.

Brotman, S., Ryan, B., \& Cormier, R. (2003). The health and social service needs of gay and lesbian elder and their families in Canada. The Gerontologist, 43(2), 192-202.

Brotman, S., Watkins, J., \& Ryan, B. (2010). Toronto longterm care homes and services: LGBT diversity initiative documentation project (Unpublished report). Montreal, QC: McGill University.

Cahill, S., South, K., \& Spade, J. (2000). Outing age: Public policy issues affecting gay, lesbian, bisexual and transgender elders. New York, NY: National Gay and Lesbian Task Force Policy Institute.

Canada Census (2006). Family portrait: Continuity and change in Canadian families and households in 2006: National portrait: Census families. Ottawa, ON: Statistics Canada. Retrieved from http://www12.statcan.ca/censusrecensement/2006/as-sa/97-553/index-eng.cfm

Canadian Institute for Health Information (2013). Residential long-term care financial data tables. Quick Stats. Ottawa, ON: Author.

Canadian Institutes of Health Research, Natural Sciences and Engineering Research Council of Canada, and Social Sciences and Humanities Research Council of Canada. (2010, December). Tri council policy statement: Ethical conduct for research involving humans. Ottawa, ON: Interagency Secretariat on Research Ethics.

Chamberland, L. (2003). Plus on viellit, moins ça paraît: Femmes âgées, lesbiennes invisibles [The older you get, the less you are seen: Aging women, invisible lesbians]. Revue Canadienne de Santé Mentale Communautaire, 22(2), 85-103.

Chamberland, L., Beauchamp, J., Dumas, J., \& Kamgain, O. (2016). Aîné.e.s LGBT: Favoriser le dialogue sur la préparation de leur avenir et de leur fin de vie, et la prise en charge communautaire (Rapport de recherche) [LGBT Older Adults: Fostering dialogue about future and end-of-life, and care in the community (Research report)]. Montréal, QC: Chaire de recherche sur l'homophobie, Université du Québec à Montréal.

Castle, N. G. (2005). Measuring staff turnover in nursing homes. The Gerontologist, 46(2), 210-219.

Daley, A. E., \& MacDonnell, J. A. (2011). Gender, sexuality and the discursive representation of access and equity in health services literature: Implications for LGBT communities. International Journal for Equity in Health, 10(40), 1-10.

Daley, A. E., MacDonnell, J. A., \& St. Pierre, M. (2016). LGBTTQI communities and home care in Ontario [Project report]. Toronto, ON: York University.

de Vries, B. (2009). Aspects of life and death, grief and loss in lesbian, gay, bisexual, and transgender communities. In K. Doka \& A. S. Tucci (Eds.), Living with grief: Diversity and end-of-life care (pp. 243-257). Washington, DC: Hospice Foundation of America.

Donaldson, W. V., Asta, E. L., \& Vacha-Haase, T. (2014). Attitudes of heterosexual assisted living residents towards gay and lesbian peers, Clinical Gerontologist, 37(2), 167-189.

Dobbs, D., Eckert, J. K., Rubinstein, B., Keimig, L., Clark, L., Frankowski, A. C., \& Zimmerman, S. (2008). 
An ethnographic study of stigma and ageism in residential care or assisted living. The Gerontologist, 48(4), 517-526.

Fenway Institute (2017). Glossary of LGBT terms for health care teams. Boston, MA: National LGBT Health Education Center. Available at: https://www.lgbthealtheducation. org/wp-content/uploads/2016/03/LGBT-Glossary_ Jun2017.pdf

Fraher, A., \& Coffey, A. (2011). Older people's experiences of relocation to long-term care. Nursing Older People, 23(10), 23-27.

Fredriksen-Goldsen, K. I., Hoy-Ellis, C. P., Goldsen, J., Emlet, C. A., \& Hooyman, N. R. (2014). Creating a vision for the future: Key competencies and strategies for culturally competent practice with lesbian, gay, bisexual and transgender (LGBT) older adults in the health and human services. Journal of Gerontological Social Work, 14(14), 37-41.

Fredriksen-Goldsen, K. I., Kim, H.-J., Barkan, S. E., Muraco, A., \& Hoy-Ellis, C. P. (2013). Health disparities among lesbian, gay male, and bisexual older adults: Results from a population-based study. American Journal of Public Health, 130(1), 1802-1809.

Furlotte, C., Gladstone, J. W., Cosby, R. F., \& Fitzgerald, K-A. (2016). "Could we hold hands?" Older lesbian and gay couples' perceptions of long-term care homes and home care. Canadian Journal on Aging, 35(4), 432-446.

Gardner, A. T., de Vries, B., \& Mockus, D. S. (2014). Aging out in the desert: Disclosure, acceptance and service use among midlife and older lesbians and gay men. Journal of Homosexuality, 61(1), 129-144.

Grant, J. M. (2010). Outing age 2010: Public policy issues affecting lesbian, gay, bisexual, and transgender elders. Washington, DC: National Gay and Lesbian Task Force Policy Institute.

Grant, J. M., Mottet, L. A., Tanis, J., Harrison, J., Herman, J. L., \& Keisling, M. (2011). Injustice at every turn: A report of the national transgender discrimination survey. Washington, DC: National Center for Transgender Equality and National Gay and Lesbian Task Force.

Hébert, B., Chamberland, L., \& Enriquez, M. C. (2013). Les aîné-es trans: Une population émergente ayant des besoins spécifiques en soins de santé, en services sociaux et en soins liés au vieillissement [Trans seniors: An emerging population with specific needs in health care, social services and aging-related care]. Frontières, 25(1), 57-81.

Hébert, B., Chamberland, L., \& Enriquez, M. C. (2015). Mieux intervenir auprès des aîné.e.s trans [Rapport de recherche] [Offering services and care to trans elders (Research report)]. Montréal, QC: Chaire de recherche sur l'homophobie, Université du Québec à Montréal et Aide aux Trans du Québec.

Hsieh, H.-F., \& Shannon, S. E. (2005). Three approaches to qualitative content analysis. Qualitative Health Research, 15(9), 1277-1288.
Hughes, A. K., Harold, R. D., \& Boyer, J. M. (2011). Awareness of LGBT issues among aging services network providers, Journal of Gerontological Social Work, 54(7), 659-677.

Jackson, N. C., Johnson, M. J., \& Roberts, R. (2008). The potential impact of discrimination fears of older gays, lesbians, bisexuals and transgender individuals living in small-to moderate-sized cities on long-term health care. Journal of Homosexuality, 54(3), 325-339.

James, S. E., Herman, J. L., Rankin, S., Keisling, M., Mottet, L., \& Anafi, M. (2016). The report of the 2015 U.S. Transgender survey. Washington, DC: National Centre for Transgender Equality.

Johnson, M. J., Jackson, N. C., Arnette, J. K., \& Koffman, S. D. (2005). Gay and lesbian perceptions of discrimination in retirement care facilities. Journal of Homosexuality, 49(2), 83-102.

Jones, R. L. (2011). Cluster 3: Bisexuality through the lifespan. Imagining bisexual futures: Positive, non-normative later life. Journal of Bisexuality, 11(2-3), 245-270.

Justice Quebec. (2011). Government action plan against homophobia 2011-2016. Retrieved from https://www.justice.gouv. qc.ca/fileadmin/user_upload/contenu/documents / En_Anglais_/centredoc/publications/ministere/plansactions/plan_action_homo_AN.pdf

Justice Quebec. (2017). Government action plan against homophobia and transphobia 2017-2022. Retrieved from https://www. justice.gouv.qc.ca/fileadmin/user_upload/contenu / documents/En__Anglais_/centredoc/publications / ministere/plans-actions/plan_action_homo_EN.pdf

Kane, R. L., \& Kane, R. A. (2005). Ageism in healthcare and long-term care. Generations, 29(3), 49-54.

Lee, M. G., \& Quam, J. K. (2013). Comparing supports for LGBT aging in rural versus urban areas. Journal of Gerontological Social Work, 56(2), 112-126.

MacDonnell, J., \& Daley, A. (2015). Examining the development of positive space in health and social service organizations: A Canadian exploratory study. Journal of Gay and Lesbian Social Services, 27(3), 263-301.

McFarland, P. L., \& Sanders, S. (2003). A pilot study about the needs of older gays and lesbians. Journal of Gerontological Social Work, 40(3), 67-80.

MetLife Mature Market Institute \& The Lesbian and Gay Aging Issues Network of the American Society on Aging. (2010). Out and aging: The MetLife study of lesbian and gay baby boomers. Journal of GLBT Family Studies, $6(1), 40-57$.

Moore, C. M. (1987). Group techniques for idea building. Newbury Park, CA: Sage.

Moore, D. (2009). Designing long-term care for lesbian, gay, bisexual, transsexual and transgender people. In P. Armstrong, M. Boscoe, B. Clow, K. Grant, M. HaworthBrockman, B. Jackson, ... \& J. Springer (Eds.), A place to 
call home: Long-term care in Canada, (pp. 104-110). Halifax, NS: Fernwood.

Muraco, A., \& Fredriksen-Goldsen, K. (2011). "That's what friends do:" Informal caregiving for chronically ill lesbian, gay, and bisexual elders. Journal of Social and Personal Relationships, 28, 1073-1092.

National Institute on Aging. (2006). Dramatic changes in U.S. aging highlighted in new census. NIH report. Washington, DC: National Institutes of Health, U.S. Department of Health and Human Services.

National Senior Citizens Law Center. (2011). LGBT older adults in long-term care facilities: Stories from the field. Washington, DC: Author.

New York Department of Health and Mental Hygiene. (2007). LGBT health and human services needs in New York, NY: Author.

Ontario Long-Term Care Homes Act (2007, c. 8). Retrieved from: https://www.ontario.ca/laws/statute/07108.

Porter, K. E., \& Krinsky, L. (2014). Do LGBT aging trainings effectuate positive change in mainstream elder service providers? Journal of Homosexuality, 61(1), 197-216.

Ross, E., Scott, M., \& Wexler, E. (2003). Scan on the health and housing needs of ageing lesbians. Toronto, ON: Older Lesbians in Valued Environments and Sherbourne Health Centre.

Services and Advocacy for GLBT Elders (SAGE) (2014). Out $\mathcal{E}$ visible. The experiences and attitudes of lesbian, gay, bisexual and transgender older adults, ages 45-75. New York, NY: Author.
Smith, L. A., McCaslin, R., Chang, J., Martinez, P., \& McGrew, P. (2010). Assessing the needs of older gay, lesbian, bisexual, and transgender people: A service-learning and agency partnership approach. Journal of Gerontological Social Work, 53(5), 387-401.

Statistics Canada (2012). Residential care facilities 2009/2010. Ottawa, ON: Author.

Stein, G. L., Beckerman, N. L., \& Sherman, P. A. (2010) Lesbian and gay elders and long-term care: Identifying the unique psychosocial perspectives and challenges. Journal of Gerontological Social Work, 53(5), 421-435.

Stein, G. L., \& Bonuck, K. A. (2001). Physician-patient relationships among the lesbian and gay community. Journal of the Gay and Lesbian Medical Association, 5(3), 87-93.

Summerfield, C., \& Babb, P. (2004). Social trends. London, ENG: Office for National Statistics, London.

Sussman, T., \& Dupuis, S. L. (2014). Supporting residents moving into long-term care: Multiple layers shape residents' experiences. Journal of Gerontological Social Work, 57(5), 438-459.

Toronto Long-Term Care Homes \& Services (2008). LGBT tool kit: For creating LGBT culturally competent care at Toronto long-term care homes and services. Toronto, ON: Author.

Wallace, S. P., Cochran, S. D., Durazo, E. M., \& Ford, C. L. (2011). The health of aging lesbian, gay and bisexual adults in California. Los Angeles, CA: UCLA Center for Health Policy Research. 